\title{
Ignored adult primary hypothyroidism presenting chiefly with persistent ovarian cysts: a need for increased awareness
}

\author{
Jing Shu', Lili Xing ${ }^{1}$, Lingyan Zhang $^{2}$, Suhua Fang ${ }^{1}$ and Hefeng Huang ${ }^{3 *}$
}

\begin{abstract}
Background: Ovarian cysts are a common cause for gynecological surgery. However, some cysts are a direct result of endocrine disorders and do not require surgery. This report describes an unusual case in which persistent ovarian cysts are associated with primary hypothyroidism in a young woman. The data were collected by historytaking, physical examination, laboratory tests, ultrasound, magnetic resonance imaging and a histo-pathological study. In addition, the exons of the gene encoding the human follicle-stimulating hormone receptor were sequenced.

Discussion: The patient had markedly elevated levels of thyroid-stimulating hormone and follicle-stimulating hormone and an enlarged pituitary gland. After treatment with thyroid hormone replacement, regression of the enlarged pituitary and the ovarian cysts was observed. The possible mechanisms of the pathophysiology are discussed below.

Summary: It is necessary to consider hypothyroidism and other endocrine disorders in the differential diagnosis of adult patients with ovarian multiple cyst formation in order to prevent inadvertent ovarian surgery.
\end{abstract}

\section{Background}

Ovarian cysts are a common cause for gynecological surgery. However, some cysts are a direct result of endocrine disorders and do not require surgery. Primary hypothyroidism is a common endocrine abnormality with thyroid hormone deficiency characterized by a slackening of metabolism leading to multiple system impairment. Hypothyroidism may cause reproductive endocrinology disorders as well. Occasionally, concomitant ovarian cyst formation is reported as Van Wyk and Grumbach syndrome (VWGS) in juvenile primary hypothyroidism [1], however, it is less common in adults. Failure to recognize hypothyroidism as an etiology of ovarian cysts could lead to inadvertent oophorectomy. The authors encountered an adult case, whose chief symptom was ovarian cysts, while her hypothyroid symptoms were ignored for a long time. To determine the need for endocrine evaluation in the patients with

\footnotetext{
* Correspondence: huanghefg@hotmail.com

${ }^{3}$ Department of Reproductive Endocrinology, Women's Hospital, School of

Medicine, Zhejiang University, Hangzhou 310006, China

Full list of author information is available at the end of the article
}

multiple ovarian cysts, we supplemented this case review by elucidating the pathophysiology and treatment of this syndrome and conducting an additional literature review.

\section{Case report}

A 23-year-old female patient was referred to us with recurrent ovarian cysts after two previous operations on her ovaries. The patient underwent left oophorectomy due to acute abdominal pain caused by a left ovarian cyst rupture at the age of 19. However, 6 months later, cysts were detected in her right ovary, with the size increasing gradually to $11 \mathrm{~cm} \times 7 \mathrm{~cm} \times 7 \mathrm{~cm}$. An ovarian cystectomy was performed on her right ovary when she was 22, however, the cysts reappeared soon postoperation. For further care, she consulted our gynecology department. Upon detailed inquiry, we learned that she had slight malaise for 5 years, which was relieved by rest but was ignored. She had normal menstruation after menarche at the age of 12 , but experienced oligomenorrhea six months prior to the first surgery and continued to have irregular menstruation from that

\section{C)


point on. Past medical and family history were otherwise unremarkable.

Physical examination revealed weight of $59.5 \mathrm{~kg}$, height of $153 \mathrm{~cm}$, and BMI of $25.4 \mathrm{~kg} / \mathrm{m}^{2}$ with normal intelligence. Her development and secondary sexual characteristics were normal. Her face was puffy with some pallor, and legs revealed trace edema. Examination of her thyroid revealed a normal size and consistency. No positive sign was found in her heart, lungs, liver, kidneys, breasts or nervous system. Pelvic examination revealed a painless palpable mass sized $6 \mathrm{~cm} \times 5 \mathrm{~cm} \times 5$ $\mathrm{cm}$ in her right adnexal area.

Initial laboratory investigations in the clinic showed normochromic anemia and unremarkable liver function tests, except for a slight rise in GST (Table 1). A lipid profile revealed dyslipidemia. A reproductive hormone test on the day of referral ( 66 days from the beginning of her last menstruation) showed elevated levels of FSH and PRL in addition to markedly low levels of LH and T. Abdominal ultrasound revealed mild ascites and an enlarged right ovary of $6 \mathrm{~cm} \times 5 \mathrm{~cm} \times 4 \mathrm{~cm}$ with multiple cysts divided by septa (Figure 1A). The serum level of CA-125 was normal. Considering endocrine abnormality, further examinations were performed, and the results were consistent with severe autoimmune hypothyroidism. A biochemical test detected unusually high TSH and markedly low $\mathrm{T}_{3}$ and $\mathrm{T}_{4}$ levels. Both antithyroid peroxidase and antithyroglobulin antibodies were positive. Ultrasound of the thyroid revealed both lobes to have an irregular shape with coarse texture. Electrocardiogram revealed sinus bradycardia (56 bpm). An elevated cardiac enzyme profile and cardiomegaly detected by chest $x$-ray revealed myocardial damage, although the patient's cardiac ejection fraction was in the normal range, as measured by echocardiogram. Brain magnetic resonance imaging (MRI) showed a compensatory hypertrophic pituitary gland, which compressed the optic chiasm and stalk (Figure 2A). However, the patient had no visual field defect. No positive findings were observed in relation to levels of corticotrophin, cortisol, immunoglobulins or other autoantibodies.

On review of her previous medical records, several signs associated with a diagnosis of hypothyroidism were found, suggesting a long history of hypothyroidism.

Table 1 Clinical information of adult hypothyroidism associated with multiple ovarian cysts

\begin{tabular}{|c|c|c|c|c|c|}
\hline Author & Yamashita Y & Taher BM & Bassam T & Kubota K & This case \\
\hline Report year & 2001 & 2004 & 2006 & 2008 & 2011 \\
\hline Age & 19 & 22 & 19 & 21 & 23 \\
\hline Chief presentation & $\begin{array}{l}\text { Irregular cycle } \\
\text { Weight gain }\end{array}$ & Acute abdomen & Abdomen pain & Abdomen pain & $\begin{array}{l}\text { Acute abdomen } \\
\text { Persistent cysts }\end{array}$ \\
\hline $\mathrm{Hb}$ & 106 & - & - & 87 & $87(110-150)$ \\
\hline TSH & $132.75(0.48-4.82)$ & $>100(0.47-5.01)$ & $4191(0.47-5.01)$ & $1840.6(0.5-5.5)$ & $>100(0.34-5.6)$ \\
\hline $\mathrm{FT}_{3}$ & $3.08(6.01-8.47)$ & - & - & - & $2.00(3.85-6.01)$ \\
\hline $\mathrm{FT}_{4}$ & $3.86(14.16-24.45)$ & $<5(9.1-23.8)$ & Undetectable & $0(10.42-27.41)$ & $2.06(7.46-21.11)$ \\
\hline FSH & 3.8 & 9.8 & 14 & 9.7 & 19.84 \\
\hline TPO-Ab & $2.0(0-0.3)$ & - & - & 100 & $108.7(0-5.16)$ \\
\hline TG-Ab & - & - & - & 102400 & $83.7(0-4.11)$ \\
\hline $\mathrm{LH}$ & 1.6 & 12.6 & 1.1 & $<0.5$ & 0.26 \\
\hline$E_{2}$ & 1206 & 105.9 & 127.5 & 601 & 132 \\
\hline$P R L$ & $61.5(0-26.3)$ & 71.3 & $38.1(3.8-23.2)$ & - & 36.4 \\
\hline $\mathrm{T}$ & $0.46(0.35-2.08)$ & - & - & - & $0(0.35-2.43)$ \\
\hline $\mathrm{TG}$ & - & - & - & - & $4.40(0.37-1.84)$ \\
\hline $\mathrm{TC}$ & 4.1 & - & - & $8.82(3.31-5.66)$ & $6.49(3.10-5.69)$ \\
\hline GPT & 19 & - & - & $215(6-27)$ & $23(5-45)$ \\
\hline GST & 14 & - & - & $175(13-33)$ & $39(5-35)$ \\
\hline CK & 60 & - & - & $811(45-163)$ & $1148(39-275)$ \\
\hline $\mathrm{LDH}$ & 340 & - & - & $405(119-229)$ & $413(60-213)$ \\
\hline CA125 & - & $93(<35)$ & - & $73(1-35)$ & $29(<35)$ \\
\hline Morphology of ovary & $\begin{array}{l}\text { Multiple follicles } \\
\text { R } 9 \mathrm{~cm}\end{array}$ & $\begin{array}{l}\text { Multiloculated cysts } \\
\text { R } 6 \mathrm{~cm} \\
\text { L } 5 \mathrm{~cm}\end{array}$ & $\begin{array}{l}\text { Multiple cysts } \\
\text { R } 4.5 \mathrm{~cm} \\
\text { L } 5 \mathrm{~cm}\end{array}$ & $\begin{array}{l}\text { Multiple cysts } \\
\text { R } 10 \mathrm{~cm} \\
\text { L } 4 \mathrm{~cm}\end{array}$ & $\begin{array}{l}\text { Multicystic } \\
\text { R } 6 \mathrm{~cm}\end{array}$ \\
\hline
\end{tabular}

$\mathrm{Hb}$ : hemoglobin ( $\mathrm{g} / \mathrm{l})$; TSH: thyroid stimulating hormone (mU/l); $\mathrm{FT}_{3}$ : free triiodothyronine (pmol/l); $\mathrm{FT}_{4}$ : free tetraiodothyronine (pmol/l); TPO-Ab: antithyroid peroxidase antibody (IU/ml); TG-Ab: antithyroglobulin (IU/ml); FSH: follicle-stimulating hormone (IU/l); LH: luteinizing hormone (IU/l); $E_{2}$ : estradiol (pmol/l); PRL: prolactin ( $\mathrm{ng} / \mathrm{ml})$; T: testosterone ( $\mathrm{nmol} / \mathrm{l})$; TG: total triglyceride ( $\mathrm{mmol} / \mathrm{l})$; TC: total cholesterol (mmol/l); GPT: glutamate pyruvate transaminase (IU/l); GST: glutamic-oxaloacetic transaminase (IU/I); CK: creatine kinase (IU/I); LDH: lactate dehydrogenase(IU/l); CA-125: cancer antigen 125(IU/I); R: right ovary; L: left ovary. Data in parentheses are within the normal range. 

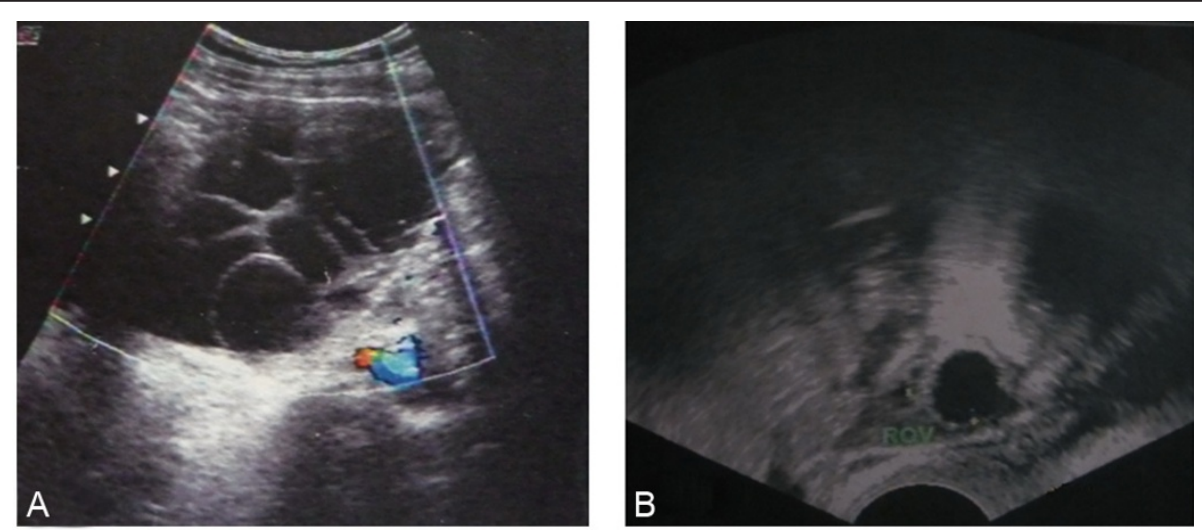

Figure 1 Pelvic ultrasound image showing right ovary before (A) and after thyroxine treatment (B)

These included mild anemia (Hgb $9.7 \mathrm{~g} / \mathrm{dl}$ ) when she underwent the first surgery, and mildly elevated levels of GST (39 IU/l), TG (2.34 mmol/l) and LDH (254 IU/ l) at the time of her second preoperative check. Histological examinations of the two previous ovarian specimens were reviewed, and both were confirmed to be follicular cysts by the presence of granulosa cells lining the cystic wall, without luteinization. The stroma was obviously edematous, but the mycoprotein stain was negative (Figure 3).

Taken together, this data suggested a diagnosis of primary hypothyroidism associated with the ovarian follicular cysts. Thyroid replacement was initiated $(25 \mu \mathrm{g}$ per day with weekly $12.5-25 \mu \mathrm{g}$ increase to a maximum 100 $\mu \mathrm{g}$ daily). The patient's symptoms improved promptly. Within 2 months, she became biochemically euthyroid and her menstruation returned to normal. Within 4 months, the level of FSH dropped to $3.48 \mathrm{IU} / \mathrm{l}$ in the early follicular stage, and the concentrations of LH, PRL and $E_{2}$ were $1.92 \mathrm{IU} / \mathrm{l}, 29.32 \mathrm{ng} / \mathrm{ml}$ and $338 \mathrm{pmol} / \mathrm{l}$, respectively. Within 7 months, the right ovarian enlargement regressed completely (Figure $1 \mathrm{~B}$ ), and the repeat MRI of the pituitary (Figure 2B) showed dramatic shrinkage. No surgical procedures were performed. However, the patient suffered from infertility two years later. She responded poorly to ovarian stimulation when
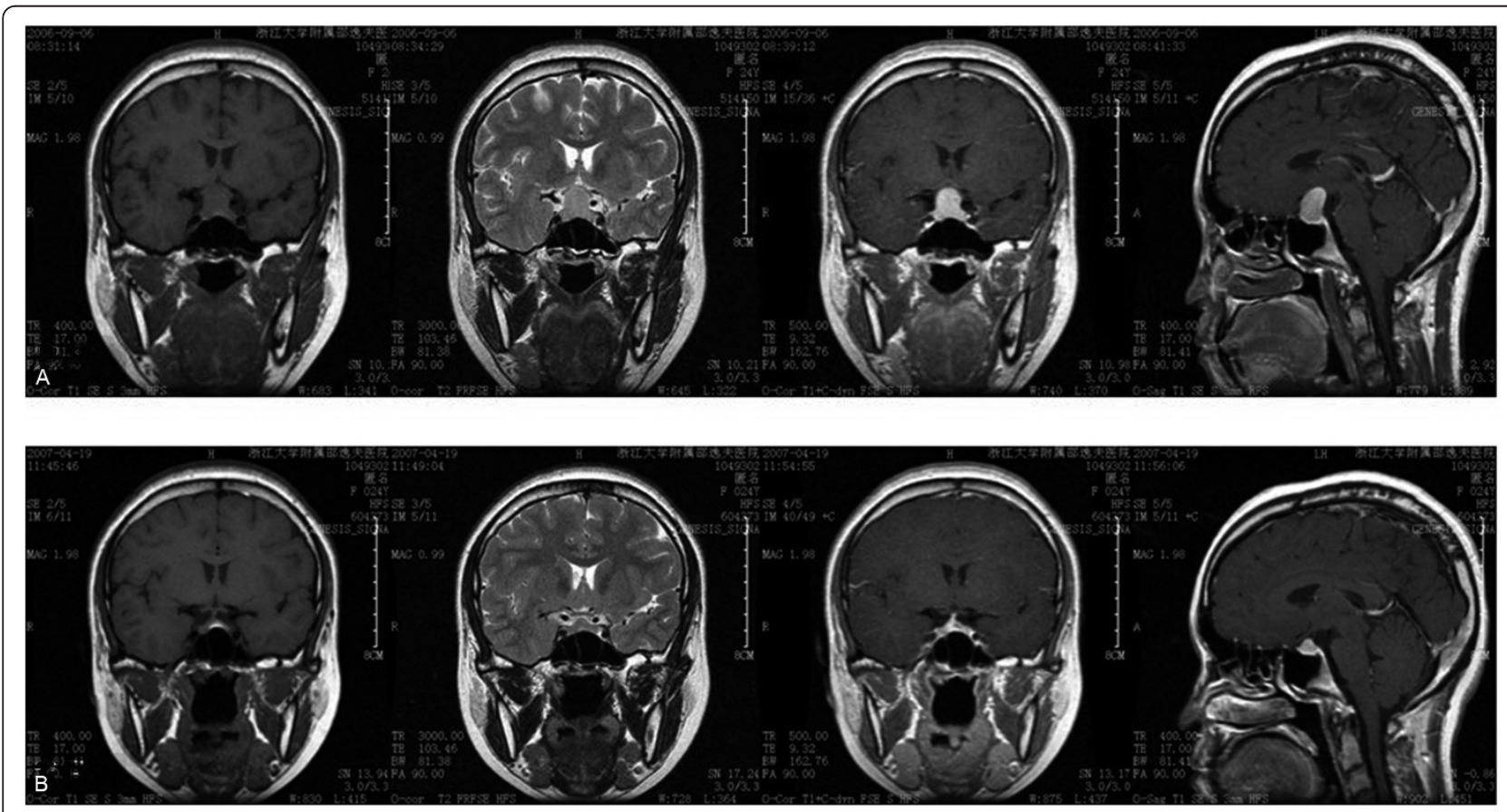

Figure 2 Head MRI before (A) and after thyroxine treatment (B) 

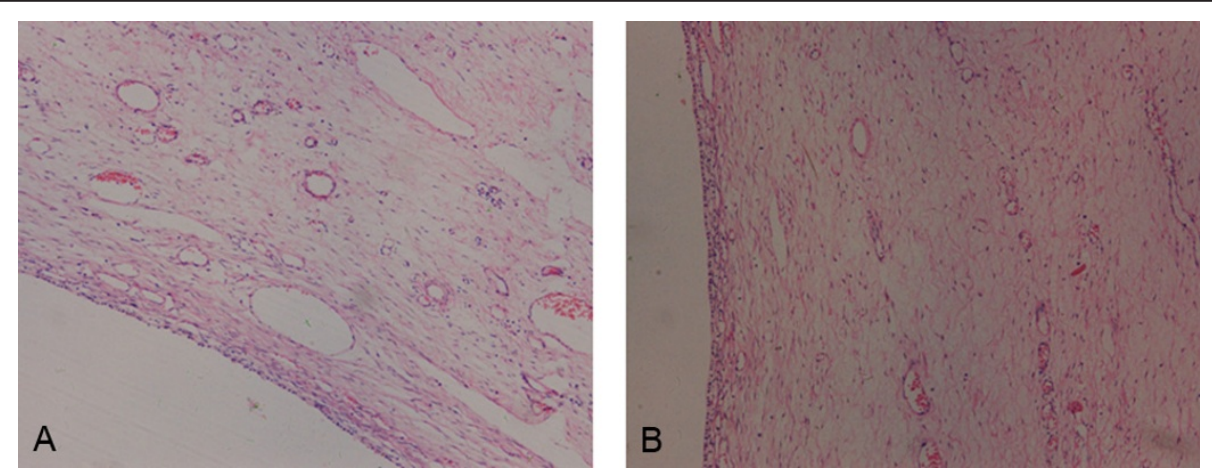

Figure 3 The ovarian cyst is lined by a simple layer of non-luteinized cells (A) with edematous stroma (B). (HE, original magnification $100 \times)$.

she underwent in vitro fertilization, suggesting her ovarian reserve had been destroyed.

DNA sequencing of FSH receptor exons did not reveal any mutations. The two common polymorphisms were homozygous for the Thr allele at position 307 and homozygous for the Asn allele at position 680. (Additional file 1, Figure S1; Additional file 2, Supplemental Methods).

\section{Discussion}

\section{Diagnosis}

Ovarian cysts are a common cause for gynecological surgery. Owing to the complexity of ovarian composition and function, the etiology of ovarian cysts can vary greatly, including benign or malignant tumors, endometriosis and inflammation, etc. Some cysts only result from reproductive endocrine dysfunction and may resolve without surgery after endocrine correction. Ovarian hyperstimulation is such a condition. With multiple follicles developing, the ultrasound images of the ovaries appear similar to multilocular cystadenoma with multiple septa. Usually, ovarian hyperstimulation syndrome (OHSS) is caused by iatrogenic superovulation. Excessive exogenous FSH stimulates multiple follicular growth simultaneously. In some rare cases, spontaneous OHSS related with pregnancy has been described as depending on activating mutations of the FSH receptor (FSHR) gene, causing ovarian hyper-responsiveness to circulating FSH or even cross-responsiveness of FSHR to hormones having a structure similar to FSH, such as human chorionic gonadotrophin (hCG) or TSH [2,3]. Eutopic or ectopic gonadotrophin adenoma secreting FSH can also present with multiple follicular cysts in ovaries $[4,5]$. Without considering these endocrine disorders as a possible etiology, clinicians are likely to assume a diagnosis of neoplasm, leading to unnecessary ovarian surgery.

Hypothyroidism is another endocrine disorder associated with ovarian hyperstimulation, yet is often ignored in its evaluation. There have been spontaneous OHSS cases reported in pregnant women with hypothyroidism [6-8]. In an animal model of hypothyroidism induced with thiouracil, animals exhibited an increased sensitivity to the cyst-formative action of pregnant mare serum gonadotrophin and hCG [9]. However, without hCG, hypothyroidism rarely results in the formation of enlarged multicystic ovaries. Since Van Wyk and Grumbach first described the combination of multicystic ovaries, juvenile hypothyroidism and precocious puberty in 1960, sporadic cases of this syndrome have been reported in pre-pubertal or adolescent girls [10-13]. For adults, only single-digit cases have been reported, from age 19 to 26 [14-17]. These cases are similar to the case presented here. The ultrasound pictures in each of these cases revealed similar typical multiple cysts of varied sizes, as would be expected in OHSS (Table 1).

Just as hypothyroidism may be missed as a cause of ovarian hyperstimulation, the presence of ovarian cysts are often overlooked in patients with hypothyroidism, particularly in nongestational adults. Without symptoms of precocious puberty such as the Van Wyk and Grumbach syndrome in young girls, it is much easier to ignore reproductive organ ultrasound evaluations in hypothyroid adults. Furthermore, without hCG triggering the release of certain ovarian vasoactive substances [18], these nongestational adults lack the typical complications of ovarian hyperstimulation, such as severe abdominal distention, serious hemoconcentration, massive ascites or pleural effusion. In the few such cases that have been reported, patients were referred to hospitals only due to too a large abdominal mass or acute abdomen.

\section{Pathophysiology}

There are several hypotheses about the mechanism of ovarian cyst formation associated with hypothyroidism. 
First, TSH, FSH and their receptors have related structures. Extremely high concentrations of TSH in hypothyroidism may be sufficient to cause the activation of FSHR. Experiments from Anasti validated that recombinant human TSH could elicit a dose-dependent cyclic adenosine monophosphate response in the in vitro human FSHR bioassay, though the concentration of TSH required for half-maximal stimulation was several logs greater than that of FSH [19]. This provides a major potential mechanism for severe hypothyroidism resulting in ovarian hyperstimulation.

A second possible mechanism may be related to a change in pituitary gonadotropin levels. Though gonadotropin levels of hypothyroid women are usually normal [20], the patients with multilocular ovaries reported by us and most other authors showed relatively high FSH and low LH levels. The mechanism of such endocrine change remains enigmatic. It is suggested that an "overlap" effect in the negative feedback response occurs, so that not only TSH but also gonadotropins are stimulated by extremely high TRH [1]. These remarkably high endogenous FSH levels can effectively stimulate the follicles. One reason for low LH levels despite elevated FSH may be that in the pituitary-hypothalamic axis LH and FSH synthesis and secretion are differentially regulated. Slow GnRH pulse frequencies favor FSH production and secretion, whereas rapid frequencies favor LH production and secretion [21-23]. It may be that hypothyroidism is associated with slow $\mathrm{GnRH}$ pulse. Blunted or delayed LH response to GnRH has been found in some hypothyroid women [20]. Another possible reason for the FSH and $\mathrm{LH}$ mismatch is that high TRH can induce hyperprolactinemia which also can impair LH pulse by intermittent reductions in GnRH secretion [24]. A third explanation may be the presence of another regulation pathway for FSH secretion, involving estrogen and activin at the pituitary level. In our case, due to the low level of $\mathrm{LH}$, the theca cells could not produce enough testosterone for granulosa cells to biosynthesize estrogen. The low estrogen status in turn enhanced FSH secretion, persistently stimulating follicular enlargment without a concomitant rise in estrogen concentrations.

A third possible mechanism has been hypothesized to be due to FSHR activating mutations permitting or amplifying the affect of hCG or TSH on the follicles. The mutations of $\mathrm{Asp}^{567}$ Asn, $\mathrm{Thr}^{449}$ Ile, $\mathrm{Thr}^{449} \mathrm{Ala}$ and Ile ${ }^{545} \mathrm{Thr}$ were found in women with spontaneous OHSS in pregnancy [25-27]. FSHR gene polymorphisms may influence FSHR protein responsiveness as well, particularly codons 307 and 680 [27]. However, Ryan sequenced the FSHR gene in eight juvenile patients with VW syndrome. No FSHR mutation was identified and no difference in the responses to $\mathrm{rFSH}$ or $\mathrm{rTSH}$ in different FSHR allelic combinations was found [12]. Likewise, in our patient, we found no FSHR exon mutations. The genotype in our case was homozygous $\mathrm{Thr}^{307}$-Asn ${ }^{680}$. While FSHR gene mutations and polymorphism may be associated with ovarian hyperstimulation, there is no evidence that they are essential to its pathogenesis.

Fourth, TSH may sensitize the ovaries to gonadotropin stimulation by stimulating nuclear thyroid receptors in the granulosa cells, thereby exacerbating ovarian hyperstimulation[28].

Fifth, myxedematous-type infiltration might also account for the interference of steroidogenesis in the ovary and contribute to ovarian cystic changes.

Despite multiple hypotheses for the association between hypothyroidism and ovarian hyperstimulation, the exact mechanism is not yet clear. It is uncertain why hypothyroidism is so common while concomitant ovarian hyperstimulation appears to be so rare. All reported cases are associated with severe hypothyroidism with TSH more than $100 \mathrm{mU} / \mathrm{l}$, and even as high as 4,191 $\mathrm{mU} / \mathrm{l}$. Besides, different pathways may function in different cases. In our case, extremely high TSH and FSH were the main causes. Furthermore, it is not fully understood why this syndrome is only seen in girls or young women. Maybe young gonads are particularly susceptible to stimulation by TSH or FSH.

\section{Treatment}

Although the precise etiopathology of this disorder remains speculative, the treatment approach is for ovarian hyperstimulation due to hypothyroidism is clear. Evidence exists that supplementation with thyroid hormone can lead to the complete regression of the multicystic ovarian enlargement, even in patients with high CA-125 levels[15]. Surgical exploration in these cases should be performed only for emergent cases such as ovarian torsion or rupture. If at the time of surgery ovarian neoplasm is suspected, precautionary frozen sectioning should be performed prior to oophorectomy. When adequate thyroid replacement therapy fails to resolve ovarian enlargement, surgical excision should be considered. Panico reported an ovarian wedge resection for persistent ovarian enlargement after adequate thyroid replacement therapy for 14 months. The histological section in their case showed a benign ovarian cyst with extensive hemorrhage and myxedematous infiltration[10]. Other treatments, such as aspiration[11], may be considered as well for persistent cysts.

\section{Summary}

Although the syndrome is very rare, profound hypothyroidism can cause multicystic ovaries in an adult. It is imperative that all health care providers, including 
gynecologists, surgeons and physicians should consider hypothyroidism and other endocrine disorders in the differential diagnosis of adult females presenting with multicystic ovarian tumors to avoid unnecessary and catastrophic ovarian resection.

\section{Additional material}

Additonal file 1: Supplemental figure S1. RFLP analysis and sequence showing the $\mathrm{Thr}^{307}$ Ala polymorphism.

Additonal file 2: Supplemental methods. Method for RFLP analysis.

\section{List of abbreviations}

WWGS: Van Wyk and Grumbach syndrome; Hb: hemoglobin; TSH: thyroid stimulating hormone; $\mathrm{FT}_{3}$ : free triiodothyronine; $\mathrm{FT}_{4}$ : free tetraiodothyronine; TPO-Ab: antithyroid peroxidase antibody; TG-Ab: antithyroglobulin antibody; FSH: follicle-stimulating hormone; LH: luteinizing hormone; $E_{2}$ : estradiol; PRL: prolactin; T: testosterone; TG: total triglyceride; TC: total cholesterol; GPT: glutamate pyruvate transaminase; GST: glutamic-oxaloacetic transaminase; CK: creatine kinase; LDH: lactate dehydrogenase; CA-125: cancer antigen 125; R: right ovary; L: left ovary; MRI: magnetic resonance imaging; hCG: human chorionic gonadotrophin; OHSS: ovarian hyperstimulation syndrome; GnRH: gonadotropin releasing hormone; FSHR: follicle-stimulating hormone receptor; Thr: Threonine; Ala: Alanine; Asn: Aspatagine; Ser: Serine.

\section{Acknowledgements}

The English language and grammar of the manuscript are corrected with the assistance of Jessica Watters, MD, Loma Linda University Medical Center, USA

\section{Author details}

'Department of Obstetrics \& Gynecology, Sir Run Run Shaw Hospital, School of Medicine, Zhejiang University, Hangzhou 310016, China. ${ }^{2}$ Department of Obstetrics \& Gynecology, Xiasha Hospital, Hangzhou 310001, China.

${ }^{3}$ Department of Reproductive Endocrinology, Women's Hospital, School of Medicine, Zhejiang University, Hangzhou 310006, China.

\section{Authors' contributions}

IS collected the clinical information and drafted the manuscript. LX carried out the PCR and RFLP. LZ participated in data collection and the statistical analysis. SF participated in the clinical diagnosis and treatment. $\mathrm{HH}$ conceived of the report, and helped to draft the manuscript. All authors read and approved the final manuscript.

\section{Competing interests}

The authors declare that they have no competing interests.

Received: 21 April 2011 Accepted: 23 August 2011

Published: 23 August 2011

\section{References}

1. Van Wyk JJ, Grumbach MM: Syndrome of precocious menstruation and galactorrhea in juvenile hypothyroidism: an example of hormonal overlap in pituitary feedback. J Pediatr 1960, 57:20.

2. Vasseur C, Rodien P, Beau I, Desroches A, Gerard C, de Poncheville L, Chaplot S, Savagner F, Croue A, Mathieu E, et al: A chorionic gonadotropin-sensitive mutation in the follicle-stimulating hormone receptor as a cause of familial gestational spontaneous ovarian hyperstimulation syndrome. N Engl J Med 2003, 349(8):753-759.

3. Montanelli L, Delbaere A, Di Carlo C, Nappi C, Smits G, Vassart G, Costagliola S: A mutation in the follicle-stimulating hormone receptor as a cause of familial spontaneous ovarian hyperstimulation syndrome. $J$ Clin Endocrinol Metab 2004, 89(3):1255-1258.

4. Shimon I, Rubinek T, Bar-Hava I, Nass D, Hadani M, Amsterdam A, Harel G: Ovarian hyperstimulation without elevated serum estradiol associated with pure follicle-stimulating hormone-secreting pituitary adenoma. $J$ Clin Endocrinol Metab 2001, 86(8):3635-3640.

5. Burgos J, Cobos P, Vidaurrazaga N, Prieto B, Ocerin I, Matorras R: Ovarian hyperstimulation secondary to ectopic secretion of follicle-stimulating hormone. Literature review prompted by a case. Fertil Steril 2009, 92(3):1168 e1165-1168.

6. Cardoso CG, Graca LM, Dias T, Clode N, Soares L: Spontaneous ovarian hyperstimulation and primary hypothyroidism with a naturally conceived pregnancy. Obstet Gynecol 1999, 93(5 Pt 2):809-811.

7. Nappi RG, Di Naro E, D'Aries AP, Nappi L: Natural pregnancy in hypothyroid woman complicated by spontaneous ovarian hyperstimulation syndrome. Am J Obstet Gynecol 1998, 178(3):610-611.

8. Borna S, Nasery A: Spontaneous ovarian hyperstimulation in a pregnant woman with hypothyroidism. Fertil Steril 2007, 88(3):705 e701-703.

9. Copmann TL, Adams WC: Ovarian gonadotropin receptors during experimental ovarian cyst formation in the rat. Biol Reprod 1981, 25(1):115-119.

10. Panico A, Lupoli GA, Fonderico F, Colarusso S, Marciello F, Poggiano MR, Del Prete M, Magliulo R, lervolino P, Lupoli G: Multiple ovarian cysts in a young girl with severe hypothyroidism. Thyroid 2007, 17(12):1289-1293.

11. Gordon CM, Austin DJ, Radovick S, Laufer MR: Primary hypothyroidism presenting as severe vaginal bleeding in a prepubertal girl. $J$ Pediatr Adolesc Gynecol 1997, 10(1):35-38.

12. Ryan GL, Feng $X$, d'Alva CB, Zhang M, Van Voorhis BJ, Pinto EM, Kubias AE, Antonini SR, Latronico AC, Segaloff DL: Evaluating the roles of folliclestimulating hormone receptor polymorphisms in gonadal hyperstimulation associated with severe juvenile primary hypothyroidism. J Clin Endocrinol Metab 2007, 92(6):2312-2317.

13. Browne LP, Boswell HB, Crotty EJ, O'Hara SM, Birkemeier KL, Guillerman RP. Van Wyk and Grumbach syndrome revisited: imaging and clinical findings in pre- and postpubertal girls. Pediatr Radiol 2008, 38(5):538-542.

14. Yamashita Y, Kawamura T, Fujikawa R, Mochizuki H, Okubo M, Arita K: Regression of both pituitary and ovarian cysts after administration of thyroid hormone in a case of primary hypothyroidism. Intern Med 2001, 40(8):751-755.

15. Taher BM, Ghariabeh RA, Jarrah NS, Hadidy AM, Radaideh AM, Ajlouni KM: Spontaneous ovarian hyperstimulation syndrome caused by hypothyroidism in an adult. Eur J Obstet Gynecol Reprod Biol 2004, 112(1):107-109.

16. Bassam $T$, Ajlouni $K$ : A case of ovarian enlargement in severe primary hypothyroidism and review of the literature. Ann Saudi Med 2006, 26(1):66-68.

17. Kubota K, Itho M, Kishi H, Igarashi S, Minegishi T: Primary hypothyroidism presenting as multiple ovarian cysts in an adult woman: a case report. Gynecol Endocrinol 2008, 24(10):586-589.

18. Kasum M: New insights in mechanisms for development of ovarian hyperstimulation syndrome. Coll Antropol 2010, 34(3):1139-1143.

19. Anasti JN, Flack MR, Froehlich J, Nelson LM, Nisula BC: A potential novel mechanism for precocious puberty in juvenile hypothyroidism. J Clin Endocrinol Metab 1995, 80(1):276-279.

20. Krassas GE, Poppe $K$, Glinoer D: Thyroid function and human reproductive health. Endocr Rev 2010, 31(5):702-755.

21. Haisenleder DJ, Dalkin AC, Ortolano GA, Marshall JC, Shupnik MA: A pulsatile gonadotropin-releasing hormone stimulus is required to increase transcription of the gonadotropin subunit genes: evidence for differential regulation of transcription by pulse frequency in vivo. Endocrinology 1991, 128(1):509-517.

22. Mistry DS, Tsutsumi R, Fernandez M, Sharma S, Cardenas SA, Lawson MA, Webster NJ: Gonadotropin-Releasing Hormone Pulse Sensitivity of Follicle-Stimulating Hormone-\{beta\} Gene Is Mediated by Differential Expression of Positive Regulatory Activator Protein 1 Factors and Corepressors SKIL and TGIF1. Mol Endocrinol 2011.

23. Ferris HA, Shupnik MA: Mechanisms for pulsatile regulation of the gonadotropin subunit genes by GNRH1. Biol Reprod 2006, 74(6):993-998.

24. Sauder SE, Frager M, Case GD, Kelch RP, Marshall JC: Abnormal patterns of pulsatile luteinizing hormone secretion in women with hyperprolactinemia and amenorrhea: responses to bromocriptine. J Clin Endocrinol Metab 1984, 59(5):941-948.

25. Smits G, Olatunbosun O, Delbaere A, Pierson R, Vassart G, Costagliola S: Ovarian hyperstimulation syndrome due to a mutation in the folliclestimulating hormone receptor. N Engl J Med 2003, 349(8):760-766. 
26. Dieterich M, Bolz M, Reimer T, Costagliola S, Gerber B: Two different entities of spontaneous ovarian hyperstimulation in a woman with FSH receptor mutation. Reprod Biomed Online 2010, 20(6):751-758.

27. Lussiana C, Guani B, Mari C, Restagno G, Massobrio M, Revelli A: Mutations and polymorphisms of the FSH receptor (FSHR) gene: clinical implications in female fecundity and molecular biology of FSHR protein and gene. Obstet Gynecol Surv 2008, 63(12):785-795.

28. Dobozy O, Csaba G, Hetenyi G, Shahin M: Investigation of gonadotropinthyrotropin overlapping and hormonal imprinting in the rat testis. Acto Physiol Hung 1985, 66(2):169-175.

doi:10.1186/1477-7827-9-119

Cite this article as: Shu et al: Ignored adult primary hypothyroidism presenting chiefly with persistent ovarian cysts: a need for increased awareness. Reproductive Biology and Endocrinology 2011 9:119.

Submit your next manuscript to BioMed Central and take full advantage of:

- Convenient online submission

- Thorough peer review

- No space constraints or color figure charges

- Immediate publication on acceptance

- Inclusion in PubMed, CAS, Scopus and Google Scholar

- Research which is freely available for redistribution

Submit your manuscript at www.biomedcentral.com/submit 